\title{
Subcutaneous Emphysema Caused by Sodium Hypochlorite plus RC-Prep
}

\author{
Masayuki Tokuda*, Yoshiko Kawakami, Yoko Morimoto-Yamashita, Mitsuo Torii \\ Department of Restorative Dentistry and Endodontology, Graduate School of Medical and Dental Sciences, \\ Kagoshima University, Kagoshima, Japan \\ Email: " mas-tok@dent.kagoshima-u.ac.jp
}

Received 6 October 2014; revised 24 November 2014; accepted 9 December 2014

Copyright $@ 2014$ by authors and Scientific Research Publishing Inc.

This work is licensed under the Creative Commons Attribution International License (CC BY).

http://creativecommons.org/licenses/by/4.0/

(c) () Open Access

\begin{abstract}
Introduction: "RC-Prep", a chemo-mechanical preparation for root canals, includes EDTA and urea peroxide as ingredients. For lubrication and its chelating effect, RC-Prep is useful as an adjunct in root canal enlargement. Furthermore, its cleaning action, due to its foaming properties in combination with sodium hypochlorite, can be useful in root canal treatment in many situations. Methods: In a case of upper gingiva swelling, we used sodium hypochlorite with RC-Prep in the treatment of an infected root canal of the left maxillary premolar at the first visit. Within 2 min after use, the patient's face became swollen. We kept the root canal open, and conducted a CT scan to investigate. Results: We diagnosed subcutaneous emphysema and prescribed 1 week of pain killers and antibiotics. The pain and swelling in the face finally resolved at $\mathbf{1 1}$ days after the incident. Conclusions: The cause of the emphysema was considered to have been the use of a sodium hypochlorite solution after using RC-Prep for an opened root apex.
\end{abstract}

\section{Keywords}

Subcutaneous Emphysema, Hypochlorite, RC-Prep, Endodontic Treatment

\section{Introduction}

Subcutaneous emphysema (SE) is one of the contingencies that occur rarely in dental treatments, which can be induced using a syringe or air turbine [1]. In many cases, SE occurs incidentally during tooth extraction, tooth crown formation, or in root canal treatments [2]-[4]. SE is caused by the introduction of air (gas) into the facial planes of connective tissue. Because of the looseness of this tissue and its distensible walls, air can accumulate in the crevices and convert them into spaces of considerable size [5]. The condition leads to swelling and crepi-

\footnotetext{
"Corresponding author.
} 
tus on palpation, and has the potential to spread along the facial planes to the periorbital, mediastinal, pericardial, and/or thoracic spaces.

We report a case of this disorder during root canal treatment, when using RC-Prep as an adjunct in root canal enlargement, and after the use of sodium hypochlorite solution in a syringe.

\section{Case Report}

A 52-year-old female presented with the chief complaint of pain associated with swelling apical to tooth \#12 (the left maxillary first premolar). Radiographic findings showed a diffuse, radiolucent lesion with loss of the lamina dura around tooth \#12 (Figure 1). First, to start the root canal treatment, we removed the full metal crown and metal core post. Then, we removed the gutta-percha point in the root canal using a $\mathrm{K}$ file. After length calculation, using Root ZX (Morita, Japan), we used RC-Prep (Hakusui, Japan) for root canal enlargement to the size of $\# 80$. The canal was irrigated with 5\% sodium hypochlorite (Antiformin, Wako), following 3\% EDTA solution (Smear Clean, Nishika, Japan) and normal saline solution in 5-mL syringes with no. 25-G blunt-end needles. As irrigation with sodium hypochlorite began on the buccal canal, the patient reacted violently, reporting that she had a very sharp pain and her face felt as though it was being blown up like a balloon. A noticeable swelling on the left side of her face was observed: the area extended laterally to the nose, reaching about $2 \mathrm{~cm}$ below the lower eyelid and below the lower lip and posterior to it. The peak of the swelling was at the center of an imaginary line drawn from the corner of the mouth to the tip of the ear (Figure 2(a), Figure 2(b)). Irrigation was stopped, and the tooth was dried with vacuum suction, and finally with paper points. The tooth was left open (Figure 2(c)). A conventional computed tomography (CT) scan is shown in Figure 3. Around the left cheek, diffuse signals were observed between the soft tissues of the lower jaw from the lower edge (Figure 3(a)). Shadow image spots showing low absorption were observed, so contamination with air (gas) was suspected in the soft tissue inside (Figure 3(b)). In the dental CT, X-ray transmission images could be seen around the root apex of the maxillary left canine; the left nasal bone and the low cortical bone adjacent to it had been partially absorbed. There was no narrowing of the pharyngeal cavity, nor deformation of the lateral pharyngeal wall or displacement (Figure 3(c)). Cefcapene $300 \mathrm{mg}$ per day for 7 days and 21 tablets of 60-mg loxonin, as an analgesic, were prescribed, and the patient was asked to return the next day. At $20 \mathrm{~h}$ after the episode, she was seen again; she said that the sharp pain had continued for the rest of the day, but the swelling seemed to have subsided. An examination showed that the swelling was focused on the upper face. No fluctuation was felt inside the mouth or on palpating the face. Neither ecchymosis nor closure of the eye was noted (Figure 4(a)). The sinus tract was closed (Figure 4(d)). On the sixth days, the swelling had subsided further, and moved to the lower jaw (Figure 4(b)). The pain had largely resolved. On day 11, the pain had ended completely. Slight swelling of the face and the lower jaw remained (Figure 4(c)). Root canal therapy was continued, using only saline irrigation, followed by filling with calcium hydroxide preparation, and the tooth was fitted with a temporary crown (Figure 4(e)). The postoperative sequence was uneventful, and 1 month later, the final obturation was performed with mineral trioxide aggregate (MTA, Dentsply, USA), in which the root apex was opened wide. The postoperative X-ray revealed an overextension of the MTA, extruding from both roots (Figure 5).

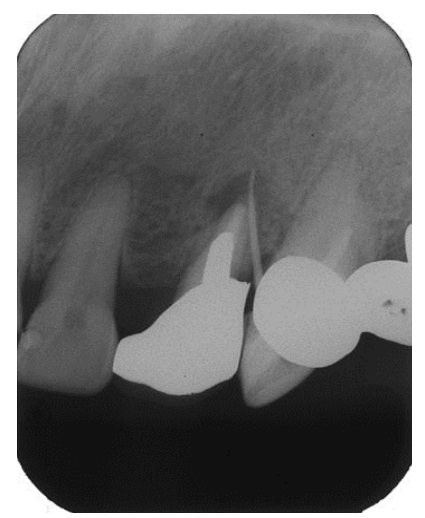

Figure 1. X-P preoperative radiograph of the left maxillary first premolar with accessory point through the fistula. 


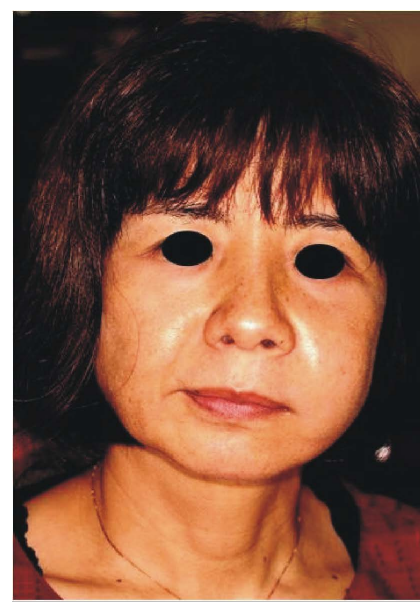

(a)

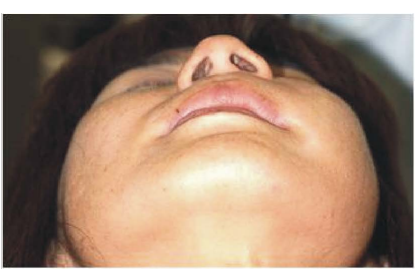

(b)

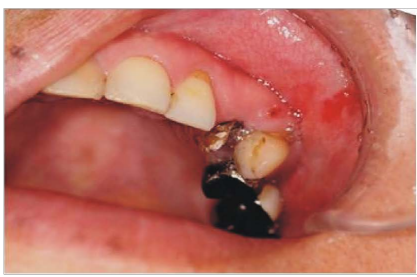

(c)

Figure 2. Clinical aspects of subcutaneous emphysema during endodontic treatment. Facial view (a), (b) and intraoral photograph (c).

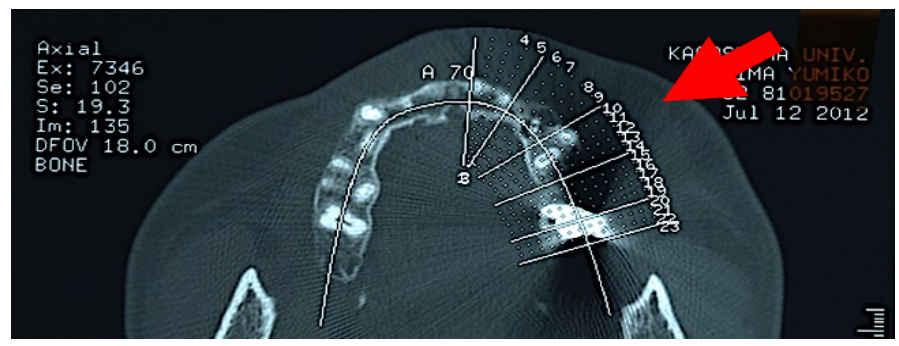

(a)

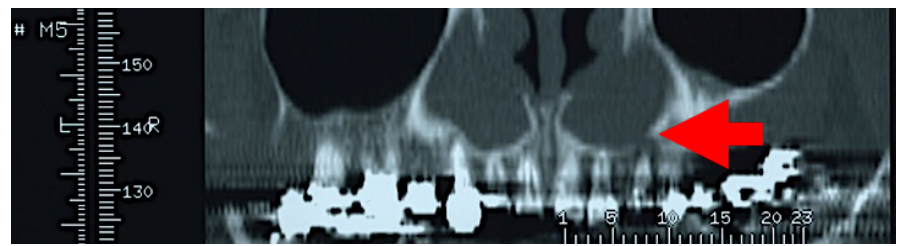

(b)

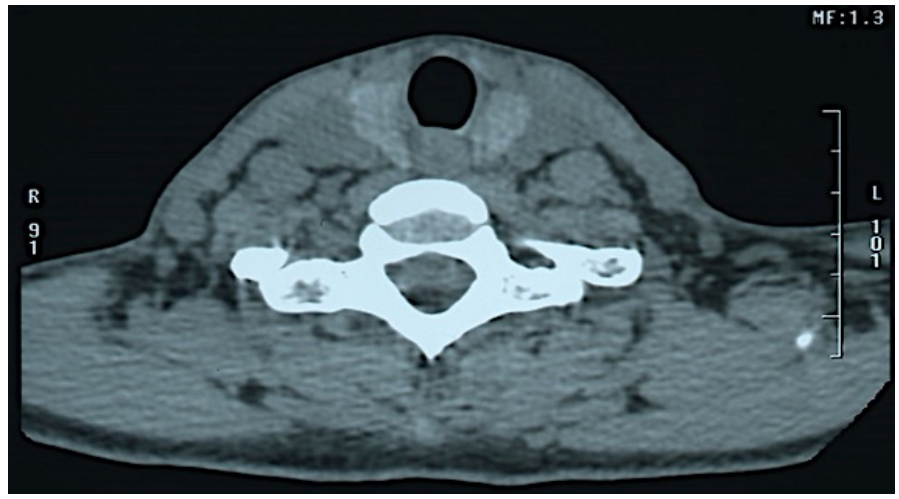

(c)

Figure 3. Computed tomography scan showed extensive gas in the soft tissue of the left cheek around the first premolar (axial view) (a); Arrow indicates the gas region. Panoramic view through the posterior. Arrow indicates the radiolucency at the apex of left maxillary premolar (b); Axial view of the pharyngeal region (c). 


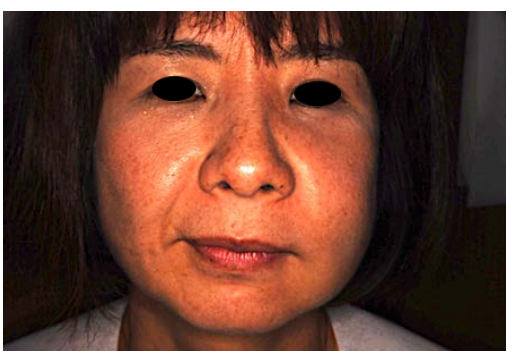

(a)

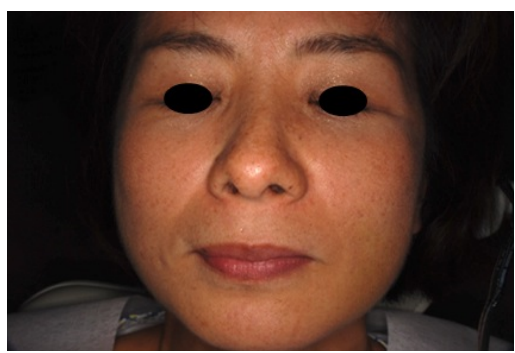

(b)

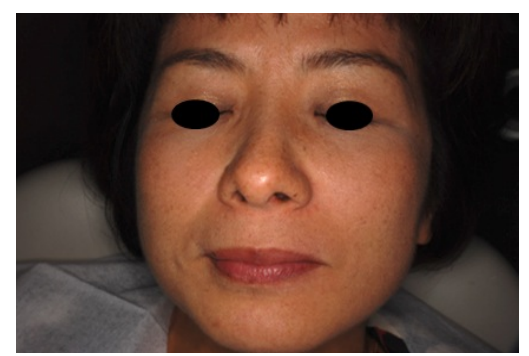

(c)

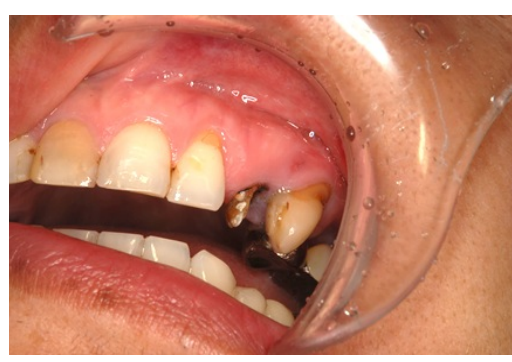

(d)

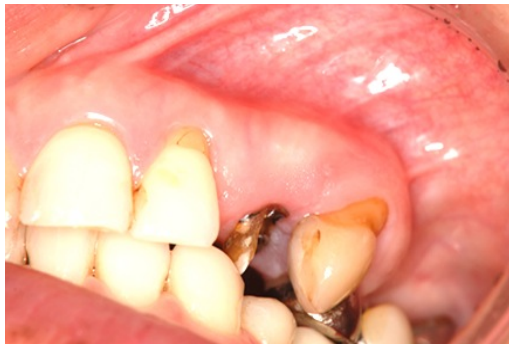

(e)

Figure 4. Facial view at 2 days (a), 6 days (b), and 11 days (c) after the first endodontic treatment. Intraoral photograph at 2 days (d) and 11 days (e).

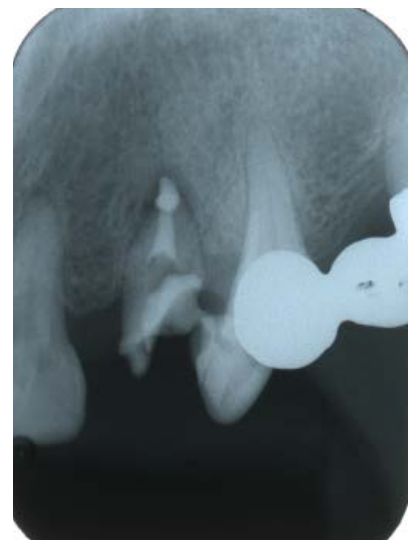

Figure 5. Postobturation radiograph after condensation.

\section{Discussion}

RC-Prep includes EDTA as a chelating agent [6] [7], which facilitates root canal preparation. Furthermore, urea peroxide is also included to generate oxygen in combination with sodium hypochlorite, which has potentially hazardous effects [8]. The combined use of EDTA and $\mathrm{NaOCl}$ is for an antimicrobial action [9]. With the foaming action, they suspend necrotic pulp tissues and root canal products. In this case, after measurement of the root canal length, and enlarging the root canal using RC-Prep, it was washed with sodium hypochlorite from a syringe.

The cause of the subcutaneous emphysema was considered to be chlorine gas, generated by a chemical reaction between sodium hypochlorite and RC-Prep and washing out the sodium hypochlorite to the outside of the root apex. Sodium hypochlorite is toxic to vital tissues [10]-[13]. It is believed that in this case, by using sodium hypochlorite in a syringe, an inflammatory response was caused in the tissue. In addition, it is thought that because RC-Prep was present, the harm caused by the action of the sodium hypochlorite was enhanced. The reason for the CT scan was to examine how widespread the emphysema was, from the cervicofacial space, including the buccal, masticator, submandibular, parapharyngeal, and retropharyngeal spaces, to the mediastinum and precordium. 
SE can be a serious complication of dental or surgical therapy. Although SE rarely causes long-term morbidity, early recognition and proper management are key to preventing progression. The presenting signs and symptoms of SE after a procedure vary. Some cases show almost immediate signs of swelling, other cases took minutes to hours after the procedure was completed before the patient became symptomatic. Patients with SE show marked swelling and discomfort where air/gas has penetrated subcutaneous tissues and even respiratory alterations if the SE has spread to the paratracheal, mediastinal, or thoracic spaces. The pathognomonic sign of SE is crepitus on palpation, which allows one to quickly rule out anaphylactic reactions or angioedema in cases of acute swelling. In patients with pneumomediastinum, a friction rub may be heard during systole on cardiac auscultation (also known as Hamman's sign). A radiographic examination of the patients should be conducted as soon as SE is detected to determine the extent and location of the emphysema. Patients with clinically significant SE should be monitored closely prior to discharge for respiratory or cardiac distress. Most cases of SE usually resolve spontaneously in 3 - 5 days with no complications or morbidity, and complete recovery in 7 - 10 days.

Clinicians should follow the manufacturer's recommendation as to the proper use and maintenance of high-pressure syringes to help prevent SE. Additionally, postoperative instructions after a dental or surgical procedure should include avoidance of coughing, smoking, blowing the nose, using straws, vomiting, or any other activity that may increase pressure in the oral cavity.

\section{Summary}

A case of facial emphysema after sodium hypochlorite with RC-Prep irrigation of the maxillary first premolar is described.

\section{Acknowledgements}

The authors deny any conflicts of interest related to this study.

\section{References}

[1] Uehara, M., Okumura, T. and Asahina, I. (2007) Subcutaneous Cervical Emphysema Induced by a Dental Air Syringe: A Case Report. International Dental Journal, 57, 286-288.

[2] Kullaa-Mikkonen, A. and Mikkonen, M. (1982) Subcutaneous Emphysema. The British Journal of Oral Surgery, 20, 200-202. http://dx.doi.org/10.1016/S0007-117X(82)80039-5

[3] Stuart McKenzie, W. and Rosenberg, M. (2009) Iatrogenic Subcutaneous Emphysema of Dental and Surgical Origin: A Literature Review. Journal of Oral and Maxillofacial Surgery, 67, 1265-1268. http://dx.doi.org/10.1016/j.joms.2008.12.050

[4] Kim, Y., Kim, M.R. and Kim, S.J. (2010) Iatrogenic Pneumomediastinum with Extensive Subcutaneous Emphysema after Endodontic Treatment: Report of 2 Cases. Oral Surgery, Oral Medicine, Oral Pathology, Oral Radiology, and Endodontology, 109, e114-e119. http://dx.doi.org/10.1016/j.tripleo.2009.09.013

[5] Paquette, M., Terazhalmy, G.T. and Moore, W.S. (2002) Subcutaneous Emphysema. Quintessence International, 33, 478.

[6] Zehnder, M. (2006) Root Canal Irrigants. Journal of Endodontics, 32, 389-398. http://dx.doi.org/10.1016/j.joen.2005.09.014

[7] Grawehr, M., Sener, B., Waltimo, T., et al. (2003) Interactions of Ethylenediamine Tetraacetic Acid with Sodium Hypochlorite in Aqueous Solutions. International Endodontic Journal, 36, 411-415. http://dx.doi.org/10.1046/j.1365-2591.2003.00670.x

[8] Baumgartner, J.C. and Ibay, A.C. (1987) The Chemical Reactions of Irrigants Used for Root Canal Debridement. Journal of Endodontics, 13, 47-51. http://dx.doi.org/10.1016/S0099-2399(87)80153-X

[9] Byström, A. and Sundqvist, G. (1985) The Antibacterial Action of Sodium Hypochlorite and EDTA in 60 Cases of Endodontic Therapy. International Endodontic Journal, 18, 35-40. http://dx.doi.org/10.1111/j.1365-2591.1985.tb00416.x

[10] de Sermeno, R.F., da Silva, L.A., Herrera, H., Herrera, H., Silva, R.A. and Leonardo, M.R. (2009) Tissue Damage after Sodium Hypochlorite Extrusion during Root Canal Treatment. Oral Surgery, Oral Medicine, Oral Pathology, Oral Radiology, and Endodontology, 14, e46-e49. http://dx.doi.org/10.1016/j.tripleo.2008.12.024

[11] Zehnder, M., Kosicki, D., Luder, H., Sener, B. and Waltimo, T. (2002) Tissue Dissolving Capacity and Antibacterial 
Effect of Buffered and Unbuffered Hypochlorite Solutions. Oral Surgery, Oral Medicine, Oral Pathology, Oral Radiology, and Endodontology, 94, 756-762. http://dx.doi.org/10.1067/moe.2002.128961

[12] Gernhardt, C.R., Eppendorf, K., Kozlowski, A. and Brandt, M. (2004) Toxicity of Concentrated Sodium Hypochlorite Used as an Endodontic Irrigant. International Endodontic Journal, 37, 272-280.

http://dx.doi.org/10.1111/j.0143-2885.2004.00804.x

[13] Pelka, M. and Petschelt, A. (2008) Permanent Mimic Musculature and Nerve Damage Caused by Sodium Hypochlorite: A Case Report. Oral Surgery, Oral Medicine, Oral Pathology, Oral Radiology, and Endodontology, 106, e80-e83. http://dx.doi.org/10.1016/j.tripleo.2008.05.003 
Scientific Research Publishing (SCIRP) is one of the largest Open Access journal publishers. It is currently publishing more than 200 open access, online, peer-reviewed journals covering a wide range of academic disciplines. SCIRP serves the worldwide academic communities and contributes to the progress and application of science with its publication.

Other selected journals from SCIRP are listed as below. Submit your manuscript to us via either submit@scirp.org or Online Submission Portal.
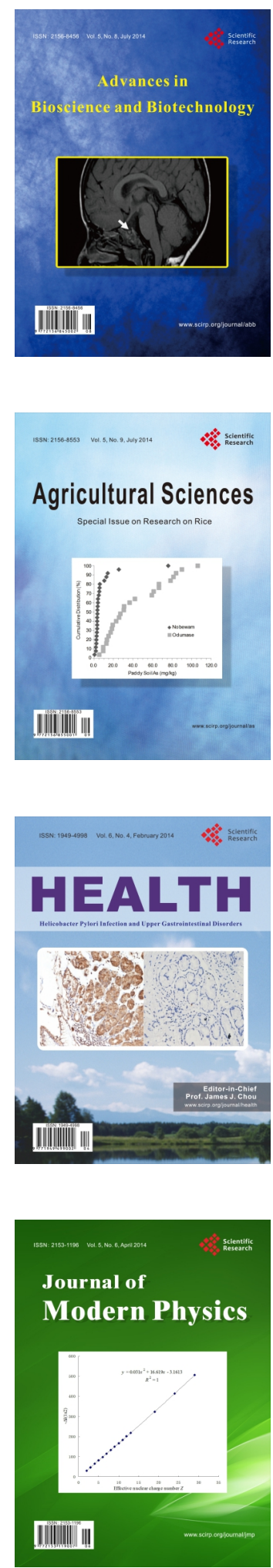
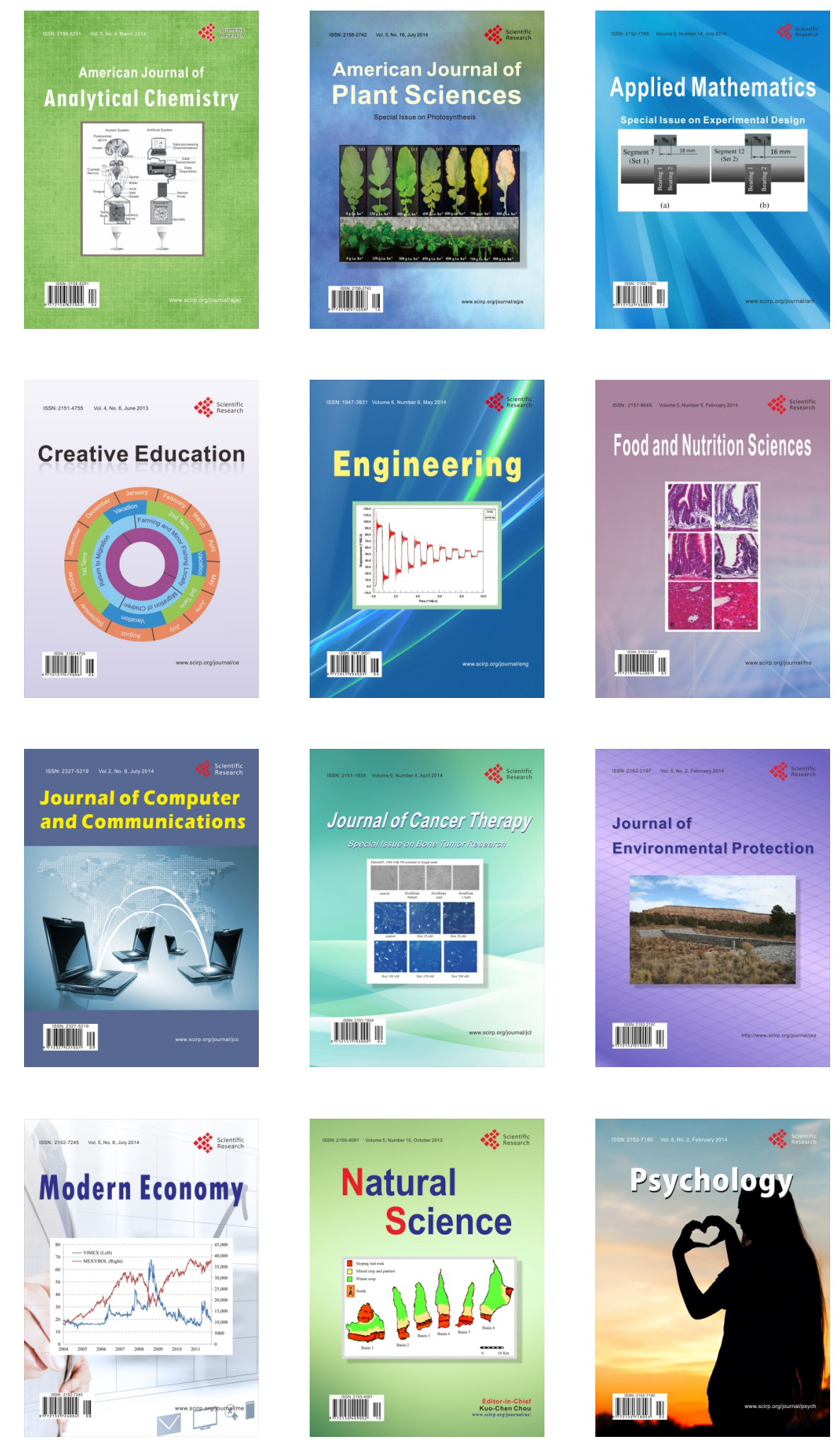